\title{
Development of multidye UV filters for OPVs using luminescent materials
}

Kettle, Jeffrey; Fernandes, Ricardo Vignoto; Bristow, Noel; Stoichkov, Vasil; Anizelli, Helder Scapin; Duarte, Jose Leonil; Laureto, Edson

\section{Journal of Physics D: Applied Physics}

DOI:

$10.1088 / 1361-6463 / 50 / 2 / 025103$

Published: 18/01/2017

Peer reviewed version

Cyswllt i'r cyhoeddiad / Link to publication

Dyfyniad o'r fersiwn a gyhoeddwyd / Citation for published version (APA):

Kettle, J., Fernandes, R. V., Bristow, N., Stoichkov, V., Anizelli, H. S., Duarte, J. L., \& Laureto, E. (2017). Development of multidye UV filters for OPVs using luminescent materials. Journal of Physics D: Applied Physics, 50(2), [025103]. https://doi.org/10.1088/1361-6463/50/2/025103

\footnotetext{
Hawliau Cyffredinol / General rights

Copyright and moral rights for the publications made accessible in the public portal are retained by the authors and/or other copyright owners and it is a condition of accessing publications that users recognise and abide by the legal requirements associated with these rights.

- Users may download and print one copy of any publication from the public portal for the purpose of private study or research.

- You may not further distribute the material or use it for any profit-making activity or commercial gain

- You may freely distribute the URL identifying the publication in the public portal ?
}

Take down policy

If you believe that this document breaches copyright please contact us providing details, and we will remove access to the work immediately and investigate your claim. 


\title{
Development of multidye UV filters for OPVs using luminescent materials
}

\section{Ricardo Vignoto Fernandes ${ }^{1}$, Noel Bristow ${ }^{2}$, Vasil Stoichkov ${ }^{2}$, Helder Scapin Anizelli ${ }^{1}$, José Leonil Duarte $^{1}$, Edson Laureto ${ }^{1 *}$, Jeff Kettle ${ }^{2}$}

${ }^{1}$ Departamento de Física, Centro de Ciências Exatas, Universidade Estadual de Londrina, 86051990 Londrina, PR, Brazil

${ }^{2}$ School of Electronic Engineering, Bangor University, Dean St., Bangor, Gwynedd, LL57 1UT, Wales, UK

*Contact author: laureto@uel.br

\begin{abstract}
Luminescence down-shifting (LDS) is used in several photovoltaic technologies aiming to improve the photon conversion efficiency (PCE) of the devices through the increase of the light harvesting in the regions of the electromagnetic spectrum where the EQE of the solar cells is poor. The aim of this work was to produce films of mixtures (blends) of two luminescent materials, dispersed in a poly-methyl methacrylate (PMMA) matrix, hoping to improve their properties both as LDS layer and as UV filter when applied on the clear, external surface of $\mathrm{P} 3 \mathrm{HT}: \mathrm{PC}_{61} \mathrm{BM}$ photovoltaic devices. The best results led to an increment of $7.4 \%$ in the PCE of the devices, and a six fold enhancement in their half-life $\left(T_{50 \%}\right)$. This study indicates that multidye LDS layers with optimized optical properties can lead to an effective improvement in the performance and operational stability of OPVs.
\end{abstract}

\section{Introduction}

The research into organic photovoltaics (OPVs) over the last decades led to a dramatic increase in their power conversion efficiencies (PCE's), with the record performance reaching $12 \%{ }^{[1]}$. The impressive improvement in efficiency is the result of research into new materials ${ }^{[2]}$, insights about processing of the layers, and understanding of the photophysical processes that occur in the devices ${ }^{[3]}$. The most studied active layer in bulk heterojunction devices is the blend formed by poly (3-hexylthiophene) and [6,6]-phenyl $\mathrm{C}_{61}$ butyric acid methyl ester ( $\mathrm{P} 3 \mathrm{HT}: \mathrm{PC}_{61} \mathrm{BM}$ ) ${ }^{[4]}$. These mixed together materials form an active layer with a large interfacial area between donor and acceptor molecules that facilitates the dissociation of the photogenerated excitons. The theoretical prediction is $23 \%$ for $\mathrm{P} 3 \mathrm{HT}: \mathrm{PC}_{61} \mathrm{BM}$ based solar cells ${ }^{[5]}$, but the best experimental results have saturated at around 6\% ${ }^{[4,6]}$. Further improvements in PCE could be reached by tandem solar cell structures ${ }^{[7]}$ or using optical enhancement techniques such as plasmonic interactions ${ }^{[8]}$, anti-reflective structures or spectral shifting ${ }^{[9,10]}$.

Despite the significant improvements in PCE, the commercialization potential is still restricted, due to the poor intrinsic stability of the organic layers ${ }^{[11-13]}$. To improve the stability of OPVs, a number of research strands are pursued including optimising the device architecture ${ }^{[14,}$ ${ }^{15]}$, substitution of hole and electron transport layers ${ }^{[16,17]}$ or improving the susceptibility to environmental degradation using barriers layers or applying UV filters ${ }^{[18,19]}$. For the latter, if the optimal material is selected, the luminescent down shifting (LDS) layer could absorb a strong intensity of UV light and remit in the visible portion of the electromagnetic spectrum can lead to an increase both the efficiency as the longevity of the devices ${ }^{[20]}$. The purpose of the LDS materials is to absorb more energetic photons and re-emit them with lower energy (higher wavelengths) in a region spectrally more matched to the external quantum efficiency (EQE) response of the device ${ }^{[21]}$. The ideal LDS materials need to simultaneously possess a variety of optical characteristics, such as (1) broadband absorption; (2) high absorption coefficient and high 
photoluminescence quantum efficiency (PLQY); (3) high transmittance and narrow band emission; (4) large Stokes shift between absorption and emission bands; and (5) long-term stability ${ }^{[21]}$. LDS materials have been applied to various photovoltaic technologies, such as monocrystalline silicon ${ }^{[22]}, \mathrm{CdTe}^{[23]}$, dye-sensitized solar cell (DSSC) ${ }^{[24]}$, OPV ${ }^{[25]}$ and perovskitebased solar cell ${ }^{[26]}$. A number of different material systems have been investigated for application in solar cells ${ }^{[27]}$, such as luminescent dyes ${ }^{[28]}$, graphene quantum dots ${ }^{[29]}$, and metal complexes ${ }^{[30]}$. Recently, Kettle et al. used a metal complex that was prepared with silver tetra fluoroborate $\mathrm{AgBF}_{4}$ and bis[(2-diphenylphosphino)phenyl] ether (POP), which have very high absorption in the UV range and high PLQY in the visible range ${ }^{[25]}$.

This paper reports the preparation of a mixing of two luminescent materials forming multidye blends dispersed in a PMMA host matrix. The investigation of their properties as LDS layers in $\mathrm{P} 3 \mathrm{HT}: \mathrm{PC}_{61} \mathrm{BM}$ OPVs was conducted through the analysis of several figures of merit calculated for both single and blends of luminescent materials. Additionally, stability tests were performed on $\mathrm{P} 3 \mathrm{HT}: \mathrm{PC}_{61} \mathrm{BM}$ devices coated with LDS blends, and the effect of these coatings on the OPV lifetime was evaluated.

\section{Experimental}

\subsection{Characterisation of LDS layer}

All luminescent materials used in this work were deposited on fused silica (Spectrosi ${ }^{\circledR}$ ) substrates supplied by UQG Optics Ltd., Cambridge UK. This glass has $>92 \%$ transmission from $300 \mathrm{~nm}$ to $2000 \mathrm{~nm}$. LDS solutions for coating were prepared by mixing the luminescent materials with commercially available poly (methyl methacrylate) (PMMA) dissolved in anisole (\#495 A8) supplied by MicroChem, at a concentration of $8 \%$ by weight. Both single layers and blends were prepared with a concentration of $2 \mathrm{mg} / \mathrm{ml}$. All solutions were left overnight on a heated magnetic stirrer at $60{ }^{\circ} \mathrm{C}$. Then the LDS films were deposited by spin coating at $2000 \mathrm{rpm}$ for $60 \mathrm{~s}$ and annealed for 15 minutes at $60{ }^{\circ} \mathrm{C}$. The average film thickness was measured at 360nm. UV-Vis absorption and photoluminescence (PL) measurements were performed on a Shimadzu UV-3600 spectrophotometer and a Horiba Scientific Fluoromax-4 spectrofluorometer, respectively. In the $\mathrm{PL}$ and PLQY measurements, the films were placed into an integrating sphere at an angle of $22.5^{\circ}$ to the excitation beam. The slits of the monochromators were set to ensure a bandpass of $1 \mathrm{~nm}$. The wavelength chosen for the excitation beam was always adjusted to the maximum of the absorbance of the film. Figures of merit for both single layers and blends were calculated. These were calculated using the equations in the supplementary information. The selection of LDS layers and combinations of the blends are shown in table 1 and 2 .

\subsection{Device fabrication and characterisation}

OPV devices were prepared on pre-patterned indium tin oxide (ITO) glass slides with a surface resistivity of $16 \Omega /$ square. The substrates were cleaned by using deionised water, acetone and isopropyl alcohol (IPA), 5 minutes each in ultrasound, and dried with nitrogen flux. The slides were then placed in an oxygen plasma for 5 minutes. The layer of the conductive zinc oxide ( $\mathrm{ZnO})$ was spin coated (in air) onto the substrate at $2000 \mathrm{rpm}$ for $60 \mathrm{~s}$ and baked at $150{ }^{\circ} \mathrm{C}$ for 1 hour on a hotplate to remove any residual solvent. Devices were fabricated in a glovebox, which maintained $\mathrm{H}_{2} \mathrm{O}$ and $\mathrm{O}_{2}$ concentrations to typically less than 0.1 part per million. Active layers of $\mathrm{P} 3 \mathrm{HT}: \mathrm{PC}_{61} \mathrm{BM}$ with weight ratios of 17:13 were prepared and dissolved in chlorobenzene with a concentration of $30 \mathrm{mg} / \mathrm{ml}$. The solutions of the active layer were then allowed to equilibrate for $24 \mathrm{~h}$ on a hot plate stirrer at $60^{\circ} \mathrm{C}$. Active layers were applied by spin coating at $1200 \mathrm{rpm}$ for 60 
s and annealed at $150^{\circ} \mathrm{C}$ for half hour in the glovebox. The electrodes were composed by thermal evaporation of $10 \mathrm{~nm}$ of molybdenum trioxide $\left(\mathrm{MnO}_{3}\right)$ and $150 \mathrm{~nm}$ of silver (Ag), both supplied by K-Tech Ltd., UK. A scheme of the device is shown in figure 1, where is also indicated the LDS layer applied on the device.

Devices were tested using an ABB Newport solar simulator with $100 \mathrm{~mW} / \mathrm{cm}^{2}$ AM1.5g (calibrated using a silicon reference cell from RERA, Netherlands). In order to ensure consistency of results, only devices with a standard within $10 \%$ of the mean value were used in experiments. External quantum efficiency (EQE) was obtained using a Bentham monochromator and stable light source. Measurements were taken every $1 \mathrm{~nm}$ using a Stanford Research System lock-in amplifier. For EQE data, the OPV was tested without the LDS, and repeated on the same device after LDS coating. Devices were non-encapsulated and the lifetime measurements were undertaken in an air-conditioned room with relative humidity of $35 \pm 5 \%$ and ambient temperature of $20 \pm 5{ }^{\circ} \mathrm{C}$. For stability testing, devices were kept at open circuit between the measurements and the $\mathrm{I}-\mathrm{V}$ measurements were made every 10 min using solar simulator irradiation. The test corresponded to the ISOS-L-2 protocol ${ }^{[31]}$.

\section{Results and Discussion}

In order to analyse and compare the different LDS materials, a number of figures of merit (FoM) have been used and are defined by Klampaftis et al. ${ }^{[9]}$ The equations to calculate these are shown in the supplementary information. Radiative Overlap (RO) measures the overlap between the absorption and photoluminescence spectra, so should be minimised. Photoluminescent Quantum Yield (PLQY) is a measurement of the efficiency of the luminescent material and it is the proportion of absorbed photons which will be emitted. The PLQY values were all obtained from thin films, so these are slightly lower than the sort of values obtained from dispersed solution. Absorption Spectral Matching (ASM) measures how well the LDS layer absorbs photons which are not utilised by the solar cell. Parasitic absorption (PA) measures the absorption of the LDS layer in the region where the solar cell performs well, and should be minimised. Finally, Emission Spectral Matching (ESM) is the measurement of how well the PL of the LDS material matches with the EQE of the solar cell. Additionally, a figure of merit was introduced to measure the quantity of UV radiation that the LDS layer absorbs, which is important to evaluate the suitability of the LDS film as a UV filter for the OPV cells. This parameter, called here as UV coverage (UV), is defined as the fraction of incident light, within the UV region (300-400 nm), which is absorbed by the LDS layer and prevented from reaching the solar cell. The exact definitions of the different FoMs are defined in section 1 of the Supplemental Information (SI). In order to evaluate realistically the effects of the LDS layers, the as measured absorbance and PL curves (i.e., without normalization procedure) were utilized in the calculations of the FoMs, as well as the AM1.5G standard spectrum.

\subsection{Characterisation of LDS materials}

In order to calculate the FoMs, it is necessary to acquire the optical absorption and PL spectra of the LDS films. For all materials used in this work, these spectra were included in the Figure S1 (Supplemental Information). As an illustration, it is shown in Figure 2 the absorbance and PL curves for films of Kremer Blue and Kremer Orange (lines with square) and Alq3 and Coumarin 153 (lines with circle) dispersed in PMMA. 
In most cases, the absorption and PL curves are well separated spectrally, which is one of the desired requirements for a high performing LDS material. The LDS properties of the layers were characterized through the calculation of the FoMs listed in section 2.1, based on the optical spectra of the films and on the EQE curve of the $\mathrm{P} 3 \mathrm{HT}: \mathrm{PC}_{61} \mathrm{BM}$ OPVs that were used in this work. The results for all the materials are shown in Table 1. The layer will have better LDS properties if it presents low values for radiative overlap (RO) and parasitic absorption (PA), and values as high as possible for emission spectral matching (ESM), photoluminescence quantum yield (PLQY), and absorption spectral matching (ASM). High values for the UV coverage (UV) parameter can be beneficial as well, because UV radiation normally provokes degradation to the organic active layers as well as to the oxides that work as carrier blocking layers. According to table 1, the best values for the RO and PA parameters were verified for the Kremer Blue, Europium complex and Alq3 films, while the films with the best values for PLQY and ESM were that composed by Kremer Orange, Alq3 and Coumarin 7. In terms of UV coverage parameter, the more indicated films were that related to DCM, Europium complex, Kremer Blue and Coumarin 153 dyes. However, the relatively high values of UV and ASM FoMs presented by the DCM film are related to its relatively high maximum optical density (O.D. around 1.2, whereas in the other films analysed in this work the maximum of the O.D. were around 0.1). This also led to the high relative value of the PA parameter for the DCM film. Furthermore, this film presented low values of ESM and very low PLQY, then DCM was not selected for the mixtures investigated in the sequence of this work. The film with the best value for the PLQY parameter was that composed by Kremer Orange.

\subsection{Characterisation of LDS blends}

As the primary aim of this work is the preparation of LDS blends, a number of luminescent materials were selected for blending. The materials were split into two groups based on their principal absorption ranges; 300-400nm - Europium complex (Eu), Kremer Blue (KB), Coumarin 153 (CO) and 400-500nm - Alq3 and Kremer Orange (KO). In Figure 2, the absorbance and PL spectra are also shown for films produced by the mixture (blend) of Co with KO (Figure $2 \mathrm{a}$ and $\mathrm{b}$, line with triangles) and KB with Alq3 (Figure $2 \mathrm{c}$ and d, line with triangles). The Co:KO blend possesses an absorbance curve that is a composition of the absorption individual materials. Due to the overlap between Co emission and KO absorption, energy transfer is possible ${ }^{[32]}$, and the $\mathrm{PL}$ curve is dominated by the $\mathrm{KO}$ emission, as the energy transfer is to the lower energy molecule. Otherwise, the absorption of KB and Alq3 cover the same portion of the UV region (300-400 nm) and there is poor overlap with the emission spectra. Thus, for KB:Alq3 blend, the absorbance curve covers the high energy portion of the solar irradiation, and the PL curves show a clear superposition of the optical response of the two materials, causing a broadening of the spectra. Such UV coverage and PL broadening should result in better optical characteristics over single dyes, as more photons outside the range of the EQE of P3HT:PCBM (450-650nm) can be spectrally shifted, ultimately leading the improved PV performance when used as an LDS layer.

The LDS properties of these blended layers were characterized through the calculation of the figures of merit with respect to the EQE curve of the $\mathrm{P} 3 \mathrm{HT}: \mathrm{PC}_{61} \mathrm{BM}$ OPVs, and is shown in Table 2. First of all, it is possible to observe that the PLQY values were substantially increased, while the values of RO and PA were significantly decreased. Both effects are beneficial for a LDS layer. The increase in PLQY, verified mainly in the mixtures of materials that presented more spectrally distinct PL curves, must be related to the enlargement of the PL spectra of the mixtures when compared with the individual components, but is also expected a contribution of the energy transfer effects between the different compounds in the mixture. Other favourable aspect is that 
the ESM values remained high, only a relatively lower value being measured for the mixture of KB with Eu. However, the UV and ASM parameters suffered a significantly decrease, which is not good for the LDS layers applied as harvesters of the more energetic solar photons and as filters for the UV radiation. Overall, the LDS blends show better improvement in the optical properties when compared to single LDS layers. Whilst a single LDS layer might show one figure of merit superior to an LDS blend, the LDS blends show better all-round performance. The implications of these FoMs for the mixtures will be discussed in Section 3.4.

\subsection{OPV performance with LDS blends}

The blends of LDS materials were prepared for application to P3HT:PC ${ }_{61} B M$ OPVs using the fabrication procedure described in section 2. The OPVs were coated with Coumarin 153:Kremer Orange (Co:KO), Kremer Orange:Europium (KO:Eu), Kremer Blue:Alq3 (KB:Alq3) and Kremer Blue:Europium (KB:Eu) films. All of these were mixed at concentrations of $1 \mathrm{mg}: 1 \mathrm{mg} / \mathrm{ml}$ in MicroChem A8. The EQE curves of the cells were then measured before and after the LDS application.

The curves of absorbance and PL of the KB:Alq3 blend, as well as the EQE curve of the $\mathrm{P} 3 \mathrm{HT}: \mathrm{PC}_{61} \mathrm{BM}$ device, are shown in Figure $3-\mathrm{a}$. It is evident that the absorbance of KB:Alq3 blend covers the UV region well and this is positive as the EQE of the P3HT:PCBM OPV is low in this region. At the same time, the ESM was relatively high due to the very good matching between $\mathrm{PL}$ and EQE curves (see table 2). However, as can be seen in Figure 3-b, the EQE curve was not signficantly altered by the application of KB:Alq3 LDS blend. As a matter of fact, none of the LDS blends major impact on the EQE, as can be seen in Figure $\mathrm{S} 2$ of the supplemental information. This is not a major issue, as a major decrease would be observed if a commercial UV filter was used. However, OPV devices with an LDS layer consisting of CO:KO and KO:Eu films presented EQE curves with a significant decrease in the region between 400-500 nm, as compared with the curves without LDS films. The decrease in the EQE curves is related to the optical absorption of the films, whose curves were also included in Figure S2, having maximum in the region of 400$500 \mathrm{~nm}$. Note also that the Co:KO and KO:Eu presented the highest values of the PA FoM, as can be seen in Table 2.

Table 3 shows the changes in performance when the LDS coatings were applied to the test devices. After the application of the LDS layers, all devices presented a decrease in the $I_{s c}$ values. There was a close dependence between the relative decreasing of $\mathrm{J}_{\mathrm{sc}}$ (Table 3 ) and the PA values of the mixtures (Table 2); for instance, the highest relative variation of $\mathrm{J}_{\mathrm{sc}}$ was verified for the Co:KO mixture, which presented the highest PA value. Such relation is expected, since the PA FoM evaluates the quantity of down-shifted photons that could be utilized by the solar cell, but instead is absorbed by the LDS layer ${ }^{[33]}$. The improvement of $7.4 \%$ in the PCE of the cell with $\mathrm{KB}: \mathrm{Alq} 3$ film is mainly related to the relative increase of $9.5 \%$ in the fill factor (FF), which is due to the combined effect of the $J_{s c}$ and $V_{o c}$ variation. The FF is likely to change as the the LDS layer may provoke a change in the solar radiation power incident on the cell, and such parameter contributes for the FF value as well ${ }^{\left[{ }^{34]}\right.}$. An additional possibility is that some UV light is incident through the KB:Alq3 film and affecting the properties of the $\mathrm{ZnO}$ interlayer, which is known to increase in conductivity upon UV exposure ${ }^{[35]}$.

However, the most important is to note that OPVs will need a UV filter for commercial applications outdoors. Previous reports indicate that $a \approx 20 \%$ drop in PCE is expected after the application of a commercial UV filter due to increased reflection ${ }^{[20,36]}$. So whilst the PCE of OPV drops when LDS layer are applied, this drop is much smaller than a commercial UV filter. 


\subsection{OPV stability with LDS blends}

Figure 4 shows the evolution of the performance parameters when tested on light soaking using AM1.5G spectrum and conforming to ISOS-L-2 standards. All devices showed rapid initial deterioration, as would be expected from non-encapsulated devices, and the PCE and $\mathrm{J}_{\mathrm{SC}}$ degradation both show exponential decay. All devices with LDS layers show an improvement in performance over the reference device; however, the KB:Alq3 film shows the best relative stability. The Jsc shows an exponential decline for all devices, with the reference devices declining fastest and the device with KB: Alq3 layer showing the slowest deterioration. This deterioration is typical of an OPV device. By applying a LDS layer, it is clear that the negative effects of UV light (i.e. photo-oxidation) is limited as less UV light passes through to the active layer, due to absorption by the LDS layer. The $V_{\text {oc }}$ stays relatively unchanged for all the devices for the first 70 hours and then it decreases rapidly for all the devices, probably indicating photo-oxidation of the active layer due to a change in HOMO level in the polymer ${ }^{[37]}$.

Table 4 shows the values for $T_{80 \%}$ and $T_{50 \%}$, with all devices having very similar values for $T_{80 \%}$ (between 1.5 and 4.7 hours) confirming the rapid initial degradation experienced by all the devices. More importantly, the device with KB:Alq3 coating had outperformed all the other devices with an average value of 70 hours for $T_{50 \%}$, against only 12 hours for the reference device. For these mixtures providing the best results for the stability, the absorbance curves cover mostly the UV region (see Figure 2), that shows the beneficial effect of the LDS layers on the stability is mainly due to the efficient absorption of the high energy photons of the solar radiation. It is known that the incidence of UV light in the presence of atmospheric oxygen leads to the photooxidation in the active layer of the device, that may act as traps/recombination centres for the photogenerated carriers ${ }^{[38]}$. Over time, the concentration of these defects increase, causing the deterioration of the device parameters. We can conclude that these blends are able to improve the lifetime of the devices, primarily due to their extended optical absorption spectra for lower wavelengths can reduce the deleterious effects of the active layer provoked by UV absorption, but also probably protecting the $\mathrm{ZnO}$ hole blocking layer ${ }^{[20]}$.

We anticipate that better results can be obtained after an optimization procedure of the optical spectra of the LDS blends. For instance, to improve the LDS properties of the blends aiming at an increase in the PV efficiency, it will mainly be necessary to maximize the PLQY of the films by optimizing the concentrations of the components ${ }^{[39]}$. On the other hand, to enhance the UV coverage parameter and so maximize the UV filter property of the LDS layers, the DO of the films need to be adjusted ${ }^{[40]}$.

\section{Conclusions}

In conclusion, we have investigated the use of blends of luminescent materials to improve the efficiency and stability of $\mathrm{P} 3 \mathrm{HT}: \mathrm{PC}_{61} \mathrm{BM}$ photovoltaic devices, taking into account the luminescence down-shifting (LDS) effect. The properties of the blends were evaluated by their Figures of Merit (FoM) obtained from measurements of relevant parameters for the LDS effect, such as radiative overlap, parasitic absorption, emission spectral matching, photoluminescence quantum yield and absorption spectral matching. An additional FoM, called here as UV coverage, was evaluated to measure the suitability of the LDS layer as an UV filter for organic devices. The LDS blends showed superior FoMs in comparison to single LDS layers, indicating that their performance on OPVs should be superior. When applied to OPV devices, an only moderate 
change in the PV performance was observed. However, commercial OPVs require UV filters which are known to lead to a $\approx 20 \%$ relative drop in performance, and therefore the LDS blends could substitute the need for a commercial UV filter. More significantly, the blended LDS layers showed a substantial effect on the OPV lifetime, demonstrating up to $600 \%$ of improvement in stability. The enhancement in stability is equated to an increased UV-light absorption by the LDS layer, leading to reduced propagation of UV into the device and thus photo-oxidation both of the active layer as the hole blocking layer. This study indicates that, by adjusting the optical spectra of the LDS films, better values for their FoMs can be obtained, which could result in even more relevant improvements in efficiency and lifetime of OPVs.

\section{Acknowledgements}

All authors would like to than the Royal Academy of Engineering for financial support via the Newton exchange, which funds collaboration between the UK and Brazil. Vasil Stoichkov would like to thank Sêr Cymru National Research Network for funding of his PhD studies. R. V. Fernandes, H. S. Anizelli, J. L. Duarte and E. Laureto would like to thank CNPq and CAPES for financial support.

\section{References}

1. Green, M.A., et al., Solar cell efficiency tables (version 48). Progress in Photovoltaics: Research and Applications, 2016. 24(7): p. 905-913.

2. Williams, S.S., et al., Nanopatterned Organic Materials for Photovoltaic Devices. une, 2016. 13: p. 15.

3. Mazzio, K.A. and C.K. Luscombe, The future of organic photovoltaics. Chemical Society Reviews, 2015. 44(1): p. 78-90.

4. Dang, M.T., L. Hirsch, and G. Wantz, P3HT: PCBM, best seller in polymer photovoltaic research. Advanced Materials, 2011. 23(31): p. 3597-3602.

5. Kirchartz, T., K. Taretto, and U. Rau, Efficiency limits of organic bulk heterojunction solar cells. The Journal of Physical Chemistry C, 2009. 113(41): p. 17958-17966.

6. Yang, X. and A. Uddin, Effect of thermal annealing on P3HT: PCBM bulk-heterojunction organic solar cells: A critical review. Renewable Sustainable Energy Rev, 2014. 30(0): p. 324-336.

7. Ameri, T., et al., Organic tandem solar cells: a review. Energy \& Environmental Science, 2009. 2(4): p. 347-363.

8. Catchpole, K. and A. Polman, Plasmonic solar cells. Optics express, 2008. 16(26): p. 21793-21800.

9. Klampaftis, E., et al., Enhancing the performance of solar cells via luminescent downshifting of the incident spectrum: A review. Solar Energy Materials and Solar Cells, 2009. 93(8): p. 1182-1194.

10. Wright, D.N., E.S. Marstein, and A. Holt. Double layer anti-reflective coatings for silicon solar cells. in Conference Record of the Thirty-first IEEE Photovoltaic Specialists Conference, 2005. 2005. IEEE.

11. Abdel-Fattah, T.M., et al., Stability study of low and high band gap polymer and air stability of PTB7: PC 71 BM bulk heterojunction organic photovoltaic cells with encapsulation technique. Synthetic Metals, 2015. 209: p. 348-354.

12. Roth, B., et al., The Critical Choice of PEDOT: PSS Additives for Long Term Stability of Roll-to-Roll Processed OPVs. Advanced Energy Materials, 2015. 5(9). 
13. Weerasinghe, H.C., et al., A stability study of roll-to-roll processed organic photovoltaic modules containing a polymeric electron-selective layer. Solar Energy Materials and Solar Cells, 2016. 152: p. 133-140.

14. Ray, B., P.R. Nair, and M.A. Alam, Annealing dependent performance of organic bulkheterojunction solar cells: A theoretical perspective. Solar Energy Materials and Solar Cells, 2011. 95(12): p. 3287-3294.

15. Hsu, H.-L., et al., Two-step thermal annealing improves the morphology of spin-coated films for highly efficient perovskite hybrid photovoltaics. Nanoscale, 2014. 6(17): p. 10281-10288.

16. Griffini, G., et al., Long-Term Thermal Stability of High-Efficiency Polymer Solar Cells Based on Photocrosslinkable Donor-Acceptor Conjugated Polymers. Advanced Materials, 2011. 23(14): p. 1660-1664.

17. Jørgensen, M., K. Norrman, and F.C. Krebs, Stability/degradation of polymer solar cells. Solar Energy Materials and Solar Cells, 2008. 92(7): p. 686-714.

18. Turkovic, V., et al., Long-term stabilization of organic solar cells using UV absorbers. Journal of Physics D: Applied Physics, 2016. 49(12): p. 125604.

19. Giannouli, M., et al., Methods for Improving the Lifetime Performance of Organic Photovoltaics with Low-Costing Encapsulation. ChemPhysChem, 2015. 16(6): p. 11341154.

20. Kettle, J., et al., Printable luminescent down shifter for enhancing efficiency and stability of organic photovoltaics. Solar Energy Materials and Solar Cells, 2016. 144: p. 481-487.

21. Huang, X., et al., Enhancing solar cell efficiency: the search for luminescent materials as spectral converters. Chemical Society Reviews, 2013. 42(1): p. 173-201.

22. Liu, J., et al., Improving spectral response of monocrystalline silicon photovoltaic modules using high efficient luminescent down-shifting Eu3+ complexes. Progress in Photovoltaics: Research and Applications, 2013. 21(4): p. 668-675.

23. Alonso-Álvarez, D., D. Ross, and B.S. Richards. Luminescent down-shifting for CdTe solar cells: A review of dyes and simulation of performance. in Photovoltaic Specialists Conference (PVSC), 2012 38th IEEE. 2012. IEEE.

24. Bella, F., et al., Performance and stability improvements for dye-sensitized solar cells in the presence of luminescent coatings. Journal of Power Sources, 2015. 283: p. 195-203.

25. Moudam, O., et al., Application of UV-absorbing silver (i) luminescent down shifter for PTB7 organic solar cells for enhanced efficiency and stability. RSC Advances, 2015. 5(16): p. 12397-12402.

26. Chander, N., et al., Reduced ultraviolet light induced degradation and enhanced light harvesting using YVO4: Eu3+ down-shifting nano-phosphor layer in organometal halide perovskite solar cells. Applied Physics Letters, 2014. 105(3): p. 033904.

27. Vashchenko, A., et al., Organic light-emitting diodes based on a series of new polythienothiophene complexes and highly luminescent quantum dots.

Semiconductors, 2016. 50(1): p. 120-124.

28. Solodovnyk, A., et al., Optimization of Solution-Processed Luminescent Down-Shifting Layers for Photovoltaics by Customizing Organic Dye Based Thick Films. Energy Technology, 2016.

29. Zhu, S., et al., The photoluminescence mechanism in carbon dots (graphene quantum dots, carbon nanodots, and polymer dots): current state and future perspective. Nano Research, 2015. 8(2): p. 355-381.

30. Wang, Z., et al., Synthesis, Structure, and Photophysical Properties of Two FourCoordinate Cul-NHC Complexes with Efficient Delayed Fluorescence. Inorganic chemistry, 2016. 55(5): p. 2157-2164. 
31. Reese, M.O., et al., Consensus stability testing protocols for organic photovoltaic materials and devices. Solar Energy Materials and Solar Cells, 2011. 95(5): p. 12531267.

32. Klampaftis, E., et al., Luminescent ethylene vinyl acetate encapsulation layers for enhancing the short wavelength spectral response and efficiency of silicon photovoltaic modules. IEEE Journal of Photovoltaics, 2011. 1(1): p. 29-36.

33. Alonso-Álvarez, D., et al., Luminescent down-shifting experiment and modelling with multiple photovoltaic technologies. Progress in Photovoltaics: Research and Applications, 2015. 23(4): p. 479-497.

34. Qi, B. and J. Wang, Fill factor in organic solar cells. Physical Chemistry Chemical Physics, 2013. 15(23): p. 8972-8982.

35. Bristow, N. and J. Kettle, Outdoor performance of organic photovoltaics: Diurnal analysis, dependence on temperature, irradiance, and degradation. Journal of Renewable and Sustainable Energy, 2015. 7(1): p. 013111.

36. Ryu, M.S., H.J. Cha, and J. Jang, Improvement of operation lifetime for conjugated polymer: fullerene organic solar cells by introducing a UV absorbing film. Solar Energy Materials and Solar Cells, 2010. 94(2): p. 152-156.

37. Kettle, J., et al., Chemical changes in PCPDTBT:PCBM solar cells using XPS and TOFSIMS and use of inverted device structure for improving lifetime performance. Solar Energy Materials and Solar Cells, 2015. 141: p. 139-147.

38. Cheng, P. and X. Zhan, Stability of organic solar cells: challenges and strategies. Chemical Society Reviews, 2016. 45(9): p. 2544-2582.

39. Wilson, L. and B. Richards, Measurement method for photoluminescent quantum yields of fluorescent organic dyes in polymethyl methacrylate for luminescent solar concentrators. Applied optics, 2009. 48(2): p. 212-220.

40. Uekert, T., et al., Nanostructured organosilicon luminophores in highly efficient luminescent down-shifting layers for thin film photovoltaics. Solar Energy Materials and Solar Cells, 2016. 155: p. 1-8. 


\begin{tabular}{|l|c|c|c|c|c|c|}
\hline \multicolumn{1}{|c|}{ LDS Material } & RO & UV & PLQY & ASM & PA & ESM \\
\hline Lumogen F red 300 & $8.5 \%$ & $9.9 \%$ & $5.8 \%$ & $19.1 \%$ & $28.3 \%$ & $40.3 \%$ \\
\hline $\begin{array}{l}\text { Lumogen F orange } \\
240\end{array}$ & $18.2 \%$ & $15.0 \%$ & $8.7 \%$ & $20.3 \%$ & $23.5 \%$ & $64.5 \%$ \\
\hline DCM & $2.7 \%$ & $57.5 \%$ & $1.6 \%$ & $75.1 \%$ & $57,5 \%$ & $39.3 \%$ \\
\hline $\begin{array}{l}\text { Kremer 94700 - } \\
\text { orange }\end{array}$ & $5.0 \%$ & $13.4 \%$ & $22.3 \%$ & $29.3 \%$ & $19,7 \%$ & $79.1 \%$ \\
\hline Coumarin 7 & $2.2 \%$ & $14.7 \%$ & $15.2 \%$ & $28.2 \%$ & $12.9 \%$ & $88.3 \%$ \\
\hline $\begin{array}{l}\text { Kremer 94737- } \\
\text { green }\end{array}$ & $8.6 \%$ & $23.4 \%$ & $11.3 \%$ & $25.5 \%$ & $17.0 \%$ & $25.5 \%$ \\
\hline Coumarin 153 & $2.9 \%$ & $29.3 \%$ & $8.4 \%$ & $22.6 \%$ & $7.3 \%$ & $84.4 \%$ \\
\hline $\begin{array}{l}\text { Kremer 94736- } \\
\text { blue }\end{array}$ & $2.5 \%$ & $31.0 \%$ & $5.7 \%$ & $10.1 \%$ & $2.6 \%$ & $70,4 \%$ \\
\hline Europium complex & $0.6 \%$ & $34.6 \%$ & $6.3 \%$ & $11.3 \%$ & $2.2 \%$ & $64.7 \%$ \\
\hline Alq3 & $1.4 \%$ & $8.9 \%$ & $12.5 \%$ & $4,7 \%$ & $2.0 \%$ & $87.2 \%$ \\
\hline
\end{tabular}

Table 1: Calculated parameters for the LDS materials.

\begin{tabular}{|c|c|c|c|c|c|c|}
\hline LDS Blends & RO & UV & PLQY & ASM & PA & ESM \\
\hline Co:KO & $1.1 \%$ & $13,2 \%$ & $20.2 \%$ & $15,4 \%$ & $7.5 \%$ & $68.9 \%$ \\
\hline KO:Eu & $1.4 \%$ & $4.0 \%$ & $30.9 \%$ & $7.8 \%$ & $4.4 \%$ & $88.8 \%$ \\
\hline KB:Eu & $1.3 \%$ & $10.6 \%$ & $25.3 \%$ & $3.7 \%$ & $0.7 \%$ & $59,6 \%$ \\
\hline KB:Alq3 & $1.1 \%$ & $10.2 \%$ & $15.9 \%$ & $4.1 \%$ & $0.9 \%$ & $77.9 \%$ \\
\hline
\end{tabular}

Table 2: Calculated parameters for blends produced by mixture of LDS materials: Coumarin153: Kremer Orange, Kremer Orange:Europium, Kremer Blue:Alq3, Kremer Blue:Europium.

\begin{tabular}{|c|c|c|c|c|}
\hline Sample & $\begin{array}{c}\text { PCE } \\
(\%)\end{array}$ & $\begin{array}{c}\mathrm{J}_{\text {SC }} \\
\left(\mathrm{mA} / \mathrm{cm}^{2}\right)\end{array}$ & $\begin{array}{c}\mathrm{V}_{\mathrm{OC}} \\
(\mathrm{V})\end{array}$ & $\mathrm{FF}$ \\
\hline $\mathrm{Co} \mathrm{KO}$ & $\begin{array}{c}2.8 \pm 0.2 \\
(\Delta=-12.5 \%)\end{array}$ & $\begin{array}{c}7.2 \pm 0.4 \\
(\Delta=-13.7 \%)\end{array}$ & $\begin{array}{c}0.61 \\
(\Delta=2.9 \%)\end{array}$ & $\begin{array}{c}0.65 \\
(\Delta=-1.0 \%)\end{array}$ \\
\hline $\mathrm{KO} \mathrm{Eu}$ & $2.9 \pm 0.2$ & $8.1 \pm 0.4$ & 0.59 & 0.61 \\
& $(\Delta=-5.0 \%)$ & $(\Delta=-6.8 \%)$ & $(\Delta=2.9 \%)$ & $(\Delta=-1.0 \%)$ \\
\hline $\mathrm{KB}: \mathrm{Eu}$ & $3.3 \pm 0.1$ & $8.9 \pm 0.2$ & 0.57 & 0.65 \\
& $(\Delta=-1.7 \%)$ & $(\Delta=-2.2 \%)$ & $(\Delta=-0.4 \%)$ & $(\Delta=1.2 \%)$ \\
\hline KB:Alq3 & $3.3 \pm 0.1$ & $8.9 \pm 0.2$ & 0.57 & 0.65 \\
& $(\Delta=7.4 \%)$ & $(\Delta=-3.7 \%)$ & $(\Delta=2.2 \%)$ & $(\Delta=9.5 \%)$ \\
\hline
\end{tabular}


Table 3: Performance indicators for the devices used for stability testing: Coumarin153: Kremer, Orange, Kremer Orange:Europium, Kremer Blue:Alq3 and Kremer Blue:Europium are the blends used as LDS coatings. Values are averaged across all 6 pixels. Values in brackets are relative changes $(\Delta s)$ and are based on each individual device's measurements before and after coating with LDS.

\begin{tabular}{|c|c|c|}
\hline Sample & $\mathrm{T}_{80 \%}$ (hours) & $\mathrm{T}_{50 \%}$ (hours) \\
\hline Reference & 1.6 & 11.8 \\
\hline Co:KO & 1.5 & 12.4 \\
\hline KO:Eu & 2.5 & 25.4 \\
\hline KB:Eu & 2.1 & 37.6 \\
\hline KB:Alq3 & 4.7 & 69.1 \\
\hline
\end{tabular}

Table 4: Degradation factors ( $T_{80 \%}$ and $T_{50 \%}$ ) derived from the light soaking experiments (ISOS-L2) for Coumarin153:Kr. Orange, Kr. Orange:Europium, Kr. Blue:Europium, Kr. Blue:Alq3 and reference. Data is averaged from two devices.

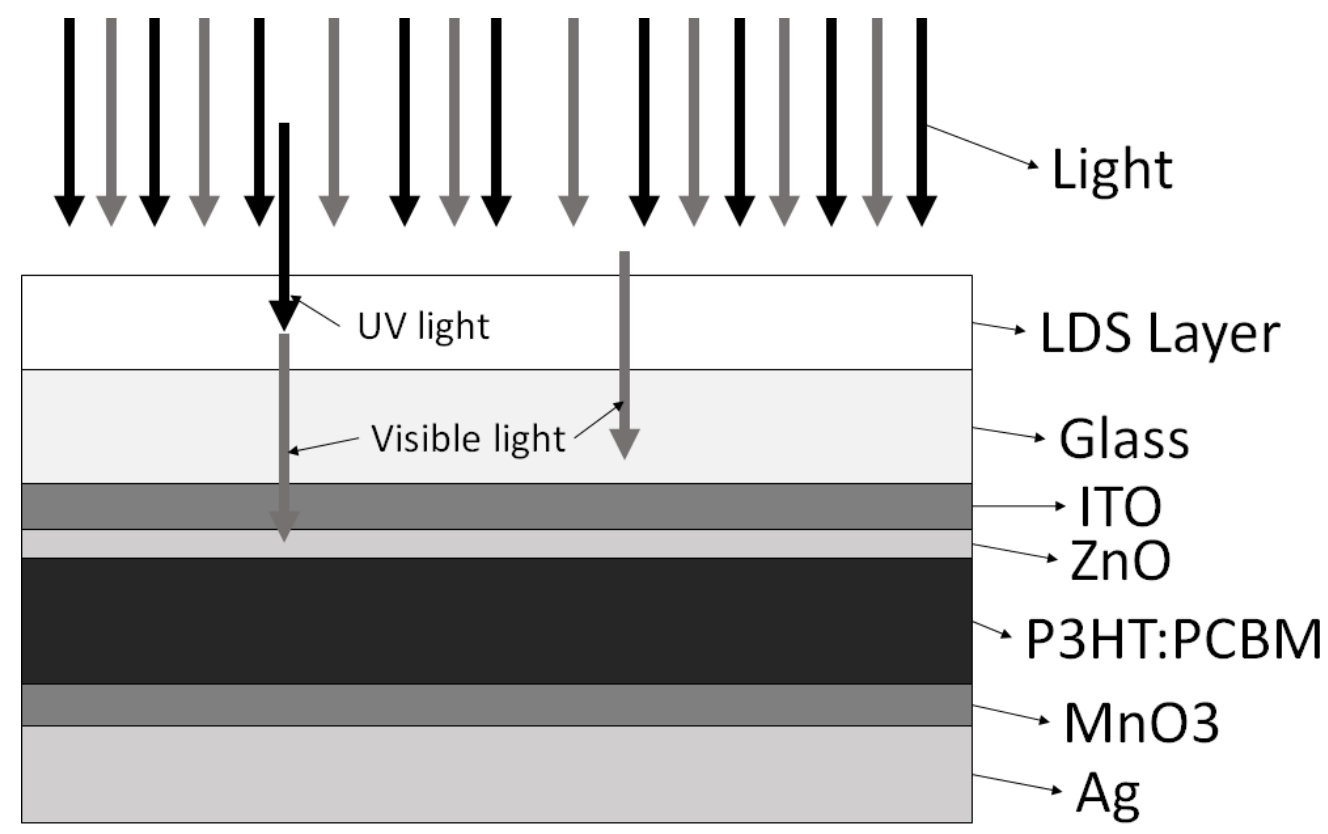

Figure 1: Schematic of the OPV used in this work including the blended LDS layer. 

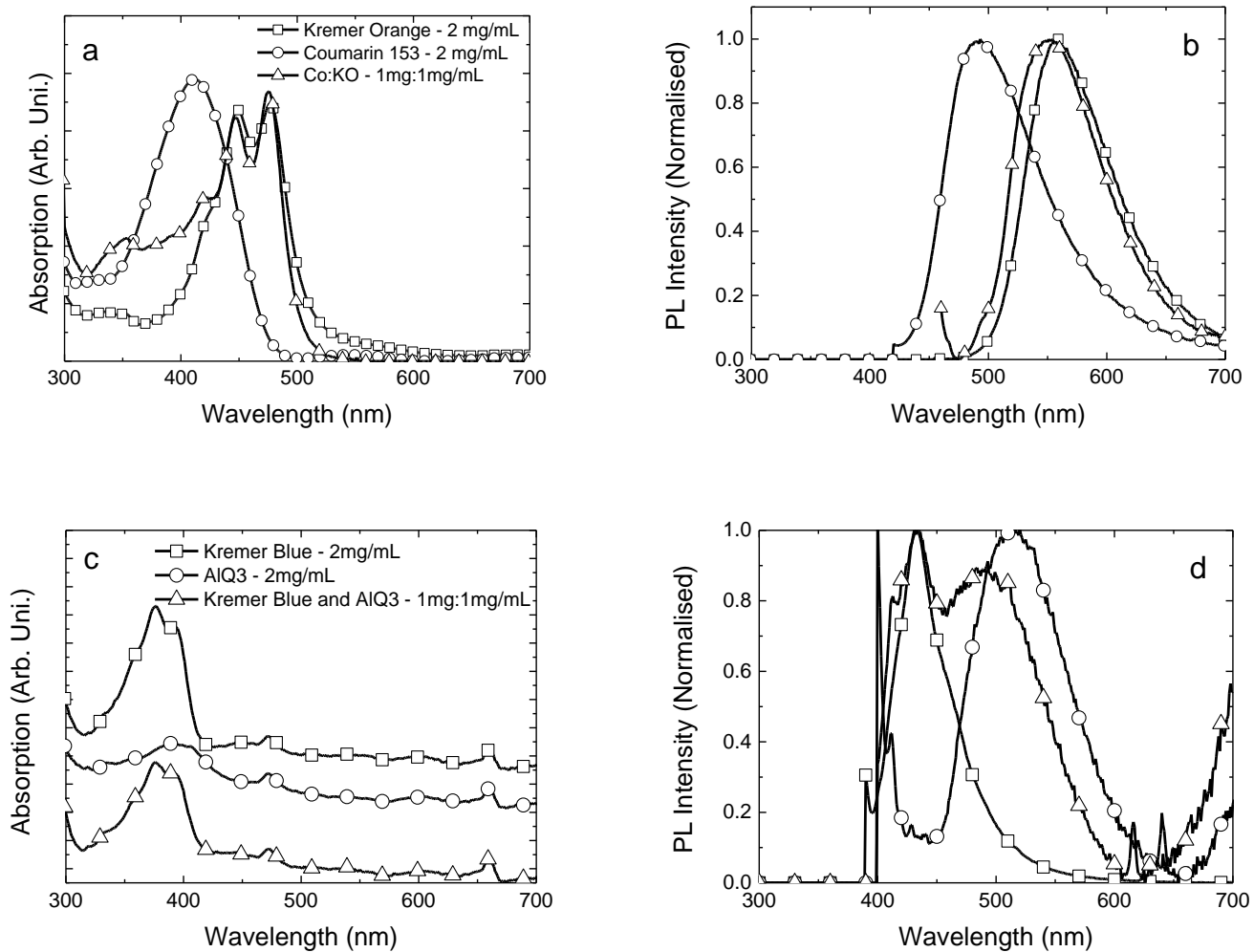

Figure 2: (a; c) Absorbance and (b; d) PL spectra for different luminescent materials and their blends. The absorbance curves in (c) have been displaced vertically for clarity. The intensities below $400 \mathrm{~nm}$ and above $650 \mathrm{~nm}$ in (d) are related to the excitation beam.
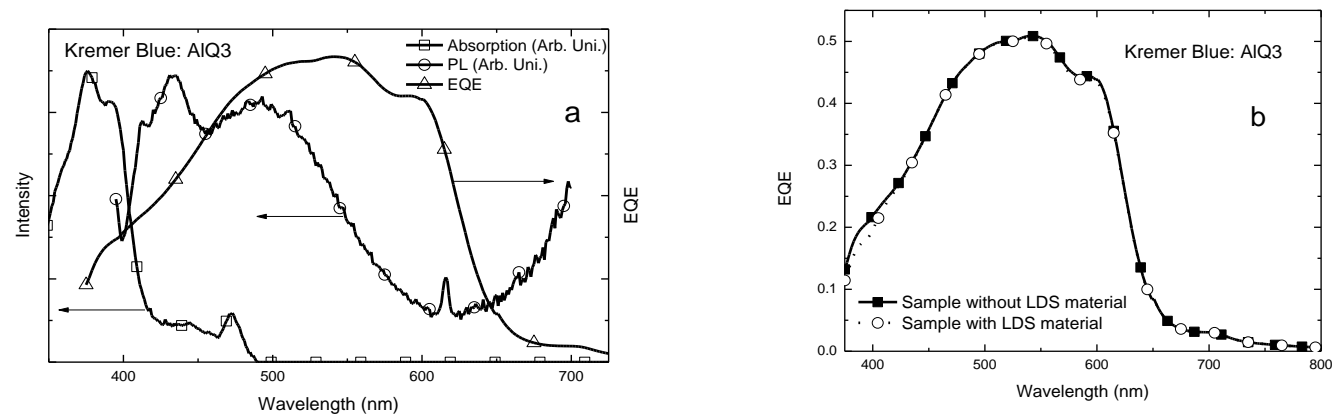

Figure 3: (a) Absorbance and photoluminescence spectra of KB:Alq3 LDS blend (left axis) and EQE of the P3HT:PC ${ }_{61} B M$ device (right axis). (b) EQE of the OPV before and after LDS blend application. 

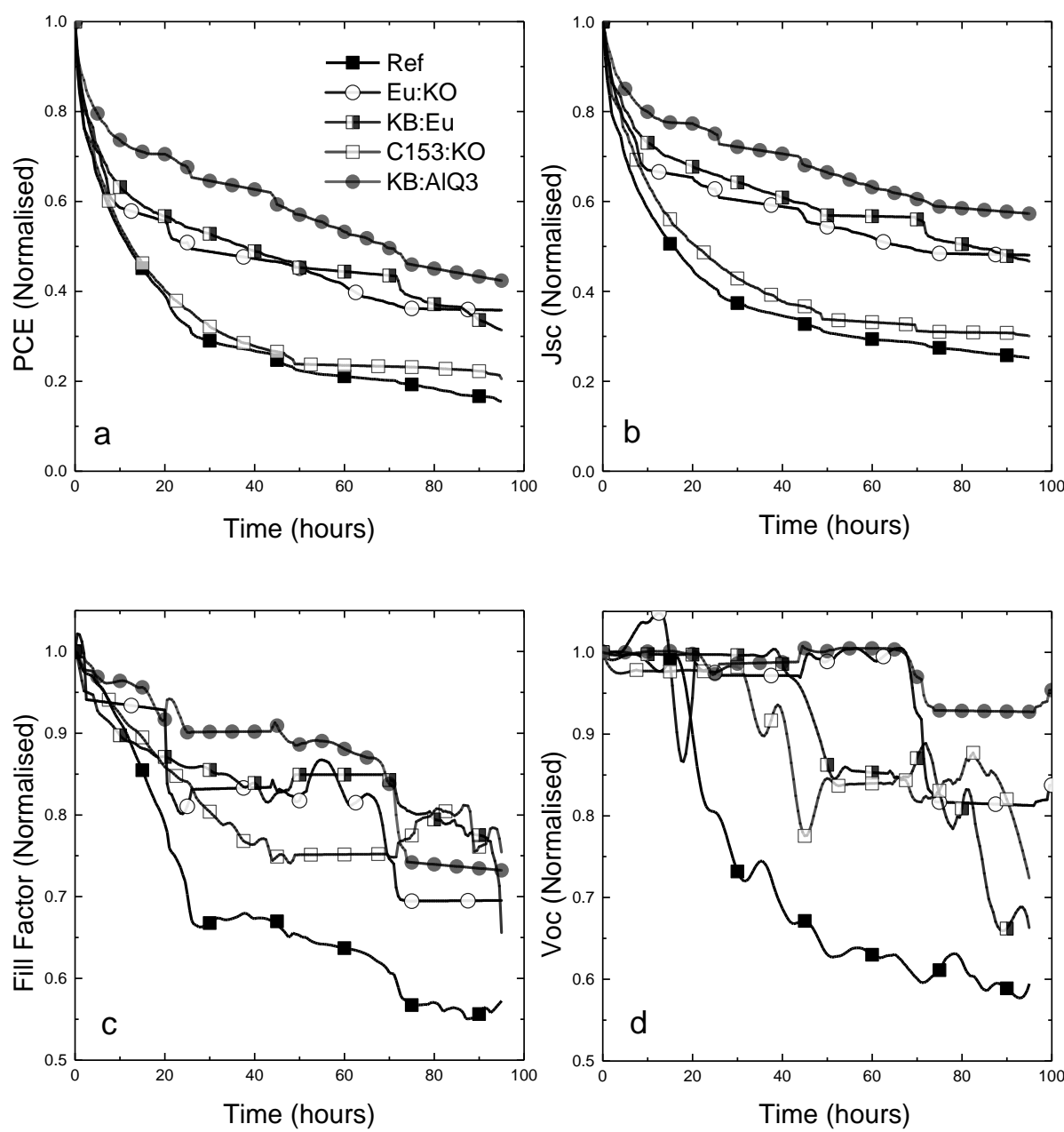

Figure 4: Change in performance parameters of the OPVs during light soaking (ISOS-L-2). Shown is (a) the Power Conversion efficiency (PCE), (b) short circuit current density (Jsc), (c) Fill factor and (d) open circuit Voltage ( $V_{\text {OC }}$ ). OPVs coated with LDS blends show increased stability compared to the reference sample. 